\title{
A Global and Local Learning Model of Transport (GALLM-T)
}

\author{
Jennifer A Hayward, James D Foster, Paul W Graham and Luke J Reedman \\ CSIRO Energy, PO Box 330 Newcastle NSW 2300, Australia \\ Email: Jenny.Hayward@,csiro.au
}

\begin{abstract}
The transport sector is accounts for 14\% of global greenhouse gas emissions (Sims, et al., 2014) but is also an essential service underpinning economic growth and societal well-being. The transport sector will therefore need to maintain or enhance mobility while transitioning to lower emission modes, fuels and technologies. Globally the road sector is the largest source $(72 \%)$ of transport emissions. Most road vehicle fuel efficiency improvements reduce the total cost of travel and therefore represent a negative abatement cost. However, other abatement opportunities such as vehicle electrification and other alternative fuels involve switching vehicle technologies, with emerging technologies initially having higher costs than the existing more emissions-intensive alternative. Uptake of these technologies helps reduce their costs through 'learning by doing', where cost reduces as uptake increases. Economies of scale in manufacturing of these vehicles will also reduce their cost. To explore the impacts of policy and economic drivers on the transport mix, CSIRO has developed a partial equilibrium model of the global transport sector, GALLM-T, which explicitly includes learning by doing.
\end{abstract}

The model uses experience curves to endogenously determine the future cost and uptake of fuel conversion technologies related to transport. GALLM-T features 13 regions, 17 fuel conversion technologies, 16 fuels, 5 passenger modes and 7 modes of freight transport. Technologies subject to learning include batteries in electric vehicles and fuel cells in fuel cell vehicles. Component learning is included where technology components have shared learning among technologies that have those components. For example, the carbon capture and storage (CCS) component in fuel production facilities is a component that is shared among all facilities that include CCS technologies.

The nonlinear experience curves have been approximated as piecewise-linear functions, and the model's 'selection' of which linear piece it is on at each point in time forms the core integer part of GALLM-T. GALLM-T is solved in GAMS as a mixed integer linear program.

This paper introduces the model and provides results from its application in the second of CSIRO's National Outlook projections, a project which explores different futures for Australia, within the global context, through quantitative scenario analysis. In the Outlook, global transport, electricity, land use and economic models are linked to generate a consistent set of inputs for national models that explore Australian outcomes in more detail.

Future demand for transport has been sourced from linking GALLM-T with a global general equilibrium model (GTAP.ME-3). GALLM-T has also been linked with CSIRO's GALLM-E model, which is used to determine the future cost and uptake of electricity generation technologies. Both GALLM-E and GALLM-T have the capacity to project uptake of batteries and fuel cells. Where this occurs in both models, the combined impact pushes these technologies down the experience curves faster, accelerating the rate of cost reduction.

This paper compares results from scenarios with moderate and strong global climate action. Illustrative results show a more than $60 \%$ share of electric drive trains in the total stock of passenger vehicles and $70 \%$ in light commercial vehicles by 2050 under both carbon price scenarios $\left(\$ 31 / \mathrm{tCO}_{2} \mathrm{e}\right.$ and $\$ 65 / \mathrm{tCO}_{2} \mathrm{e}$ by 2050$)$. There is a limited uptake of fuel cell drive trains in cars and light commercial vehicles. Low coal prices also lead to the construction of coal to liquids plants (with and without CCS), mainly providing fuel for the freight sector which continues to have a high share of diesel engines. There is a greater share of production of biofuels, which displaces conventional and alternative fossil fuels under the higher carbon price scenario from the year 2040 onwards.

Keywords: $\quad$ Learning curves, transport, electric vehicles 


\section{INTRODUCTION}

The transport sector accounts for $14 \%$ of global greenhouse gas emissions (Sims, et al., 2014) but is also an essential service underpinning economic growth and societal well-being. The transport sector will therefore need to maintain or enhance mobility while transitioning to lower emission modes, fuels and technologies as we move into the future. The road sector is the largest source of transport emissions (72\%) (Sims, et al., 2014). Most road vehicle fuel efficiency improvements reduce the total cost of travel and therefore represent a negative abatement cost. However, other abatement opportunities such as vehicle electrification and other alternative fuels involve switching vehicle technologies, with emerging technologies initially having higher costs than the existing more emissions-intensive alternative. The relative costs of different emissions reduction options, and how these might change over time, are of interest to policy makers and businesses.

This paper describes a model for simultaneously projecting changes in transport technology costs and their adoption using a regionally disaggregated global model of the transport sector which includes endogenous technology cost reduction curves. The model, GALLM-T, is applied to global greenhouse gas abatement scenarios and results for uptake of alternative fuel and vehicle technologies are described. Model inputs are included from other global model frameworks for transport demand and biomass feedstock availability.

\subsection{Fuel conversion technologies}

Research, development and deployment (RD\&D) is ongoing into alternative fuel technologies, such as biofuel refineries. While first generation biofuels can be produced using food sources (corn, wheat, seeds, etc), second and third generation biofuels can be produced using lignocellulosic feedstocks such as residues, woody weeds and pulp logs. Biofuels are considered to be the only way for air travel to be an emission-free mode. Alternative fossil fuel production technologies are also available, such as coal-to-liquids and gas-to-liquids, which may be useful under high oil prices relative to coal and gas, particularly in countries with abundant supply of these resources. These synthetic fossil petroleum and diesel technologies are however highly emissions-intensive, and would need to be coupled with carbon capture and storage (CCS) to reduce emissions. Concentrating solar thermal (CST) energy can be used in these processes to provide the heat required for reaction, thus reducing the fossil fuel footprint.

Alternative vehicle technologies include battery electric vehicles and fuel cell electric vehicles. The majority of projections comparing the future cost of battery electric and fuel cell vehicles have fuel cell vehicles costing more (Offer, Howey, Contestabile, R, \& Brandon, 2010) (Stephen \& Eaves, 2004). However, fuel cells have the advantage of fast refueling. They can also travel longer distances between refuels and can be used in all vehicle types, but particularly in heavy commercial vehicles which are not suited to full electrification (Thomas, 2009). Heavy commercial vehicles have the option of using liquefied natural gas (LNG) or compressed natural gas $(\mathrm{CNG})$ but this does require engine modifications.

There is a great deal of uncertainty around the future cost of alternative vehicle and fuel technologies. Given the recent cost decreases in lithium-ion battery technologies, some project that battery electric vehicles will have the same upfront cost as current internal combustion engine designs as early as 2018 (Campbell, 2017) whereas others are less optimistic and suggest that this cross-over point will happen between 2025 and 2029 (BNEF , 2017). Low world oil prices, which fell to $\$ 50-60 /$ bbl in the last two years from over $\$ 100 /$ bbl in 2014 (IEA, 2016), support internal combustion engine vehicles having low running costs, which may delay the uptake of battery electric and fuel cell vehicles. To explore the potential range of future costs of all of these technologies, GALLM-T has been formulated using experience curves to simultaneously project their cost and uptake under a wide range of scenarios.

\subsection{Technology Learning}

Uptake of these technologies help reduce their costs through 'learning-by-doing', where cost reduces as uptake increases. Cost reductions due to learning-by-doing have been observed since the 1930s in various technologies and processes (McDonald \& Schrattenholzer, 2001). Learning-by-doing is normally shown as the 'learning' or 'experience' curve, where the log of unit cost is plotted against the log of cumulative sales/capacity/uptake, and the slope of the curve is the negative of the learning index $b$. The equation given by:

$$
I C=I C_{0} \times\left(\frac{C C}{C C_{0}}\right)^{-b}, \quad \text { or equivalently } \quad \log (I C)=\log \left(I C_{0}\right)-b\left(\log (C C)-\log \left(C C_{0}\right)\right)
$$

where $I C$ is the unit investment cost at $C C$ cumulative capacity and $I C_{0}$ is the cost of the first unit at $C C_{0}$ cumulative capacity. The learning index $b$ satisfies $0<b<1$ and it determines the learning rate 


$$
L R=100 \times\left(1-2^{-b}\right)
$$

(typically quoted as a percentage ranging from 0 to $50 \%$ ) and the progress ratio $P R=100-L R$. All three quantities express a measure of the decline in unit cost with learning or experience.

Therefore, for each doubling in cumulative capacity of a technology, its investment cost will fall by the learning rate (Hayward \& Graham, 2013).

Emerging technologies have a higher learning rate than more mature technologies. Typically, a 20-15\% learning rate has been observed during the early stages of a technology's development, which reduce to 15 $10 \%$ by the time the technology has a market share of approximately 5\% (Grübler, Nakićenović, \& Victor, 1999). At this stage the technology is considered to be intermediate. Mature technologies have a 5-0\% learning rate.

Technologies are often a combination of several components, which could be at different stages of development and thus have different rates of learning. Efficient scale manufacturing is very important in the vehicle industry and may be a significant proportion of cost reductions (Brinsmead, Graham, Hayward, Ratnam, \& Reedman, 2015).

It is also important to identify where cost reductions are occurring to correctly attribute local versus global learning. Technologies that learn on a global scale, such as coal or gas to liquids plants, will have a different level of uptake by country to differences in local installation costs.

\section{FORMULATING EXPERIENCE CURVE APPROXIMATIONS}

A mixed-integer programming (MIP) approach is described to approximate the nonlinear experience curves by using linear constraints involving continuous and binary variables.

Modelling a nonlinear function by approximating it with a piecewise-linear function requires specifying three key ingredients: (i) the interval over which to approximate the function; (ii) where to place the breakpoints of the segments (this implies the slopes of the linear pieces if we assume continuity); and (iii) the method to decide which linear piece is 'selected' or 'active' in the model in any given state. The first is determined by the modeller's knowledge of the problem and the data provided in the problem specification. The method described by de Boor (de Boor, 1973) was used to determine (ii). In this method, a step function approximation is made to the experience curves. The optimal choice of breakpoints can be shown to be those where the height of each step is the same. An example of this is shown in Figure 1.

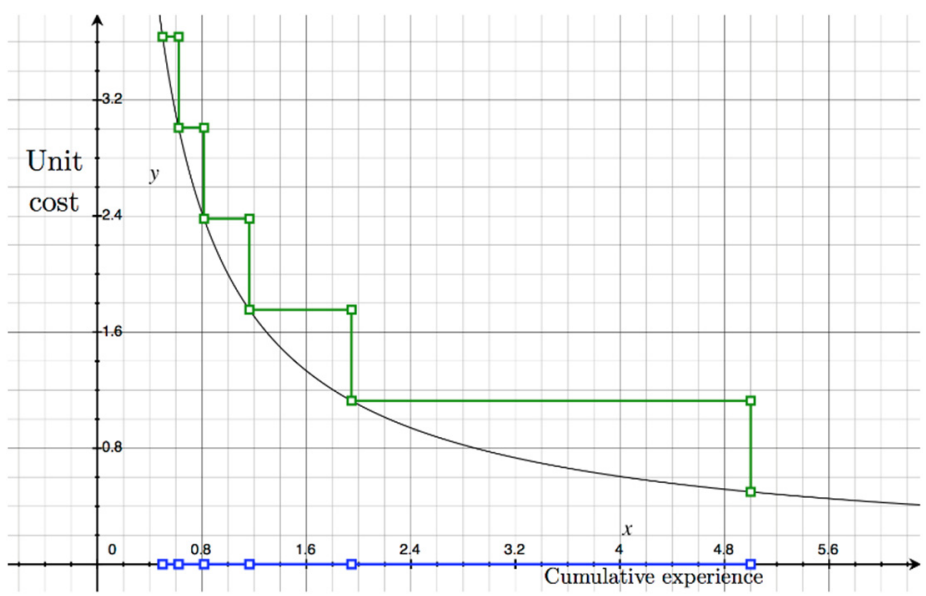

Figure 1. Step function approximation to a unit experience curve with the steps at equal heights

While the best quantity to approximate is the unit cost function, an approximation to the cumulative cost function is used: the integral of the unit cost function (Kypreos, Barreto, Capros, \& Messner, 2000). The approximation has the property that the slopes of the approximating lines are optimally as close as possible to the unit cost over each the linear segment.

In relation to (iii), a number of MIP models have been proposed for encoding piecewise-linear functions (Croxton, Gendron, \& Magnanti, 2003) (Vielma, Ahmed, \& Nemhauser, 2010). It was found that the so-called incremental model (Rebennack, 2016) was most suited for the type of experience curves employed in GALLM$\mathrm{T}$ since the problem could be decomposed by time period and relate decisions made in prior time periods in a direct way to those in later time periods. 


\section{GALLM-T}

Using the principles of technology learning, CSIRO has developed GALLM-T. It is used specifically to project the future cost and uptake of fuel conversion and alternative vehicle technologies, in different policy environments out to the year 2060. It has:

- 13 regions (Africa, Australia, China, Eastern Europe, Western Europe, Former Soviet Union, India, Japan, Latin America, Middle East, North America, OECD Pacific, Rest of Asia and Pacific);

- 17 fuel conversion technologies (batteries, fuel cells, anaerobic digestion, 1st generation biodiesel, hydroprocessed esters and fatty acids (HEFA) process for jet fuel, 1st generation ethanol, 2nd-3rd generation ethanol, Biomass-to-Liquids (BTL) via Fisher-Tropsch (FT) synthesis route or methanol route, Fast pyrolysis of lignocellulosic feedstocks, Hydrothermal liquefaction of lignocellulosic feedstocks, Coal-toLiquids (CTL) via Fischer-Tropsch (FT) or methanol route, CTL with Carbon Capture and Storage (CCS) via FT or methanol route, and Gas-to-Liquids (GTL) via FT or methanol route);

- 14 types of fuels (petrol, diesel, Liquefied Petroleum Gas (LPG), Liquefied Natural Gas/Compressed Natural Gas (LNG/CNG), biogas, ethanol, biodiesel, electricity, hydrogen, bunker, jet fuel, bio-petrol, biojet and bio-LPG);

- 6 road forms of transport (car, 2-3 wheeler, bus, light (LCV), medium (MCV) and heavy (HCV) commercial vehicle) and 6 forms of non-road transport (passenger rail, freight rail, passenger air travel, air freight, inland and coastal shipping, and international shipping).

In GALLM-T all technologies are subject to global learning except mature technologies (e.g. anaerobic digestion, and 1st generation biofuels) which are assumed to have $0.5 \%$ cost reduction per year. The learning rates of other components depend on their level of maturity (Grübler, Nakićenović, \& Victor, 1999). Some components of technologies have a 5\% learning rate (e.g. fuel synthesis in BTL, CTL and GTL), $10 \%$ learning rate (e.g. 2nd-3rd generation ethanol, BTL and CTL with CCS preparation), $15 \%$ learning rate (e.g. battery) or $20 \%$ learning rate (e.g. fuel cell). Local learning is applied to a subset of technologies (e.g. 2nd-3rd generation ethanol, BTL and CTL technologies).

Future demand for transport has been sourced from linking GALLM-T with a global general equilibrium model (GTAP-ME.3) (Smith, et al., 2017). GALLM-T has also been linked with CSIRO's GALLM-E model, which is used to determine the future cost and uptake of electricity generation technologies (Hayward \& Graham, 2013). Both GALLM-E and GALLM-T can project uptake of batteries and fuel cells. Where this occurs in both models, the combined impact pushes these technologies down the experience curves faster, accelerating the rate of cost reduction.

Fossil fuel and carbon price trajectories have been sourced from the International Energy Agency (IEA) (IEA, 2016). Biomass-based feedstock prices and upper limits for liquid fuels from $1^{\text {st }}$ generation technologies have been sourced from GLOBIOM (Global Biosphere Management Model), which has also been linked with GALLM-T. GLOBIOM models competition for land use between the agricultural, bioenergy and forestry sectors (Havlik, et al., 2011).

\subsection{Scenarios}

Two scenarios have been modelled corresponding to: (i) Scenario 1 - a high carbon price and (ii) Scenario 2 a low carbon price. Each scenario also features unique fossil fuel and feedstock prices and transport demand. These parameters differ over different regions, based on their resources, GHG emission policies, population and GDP.

\section{RESULTS}

\subsection{Scenario 1}

The global total vehicle-km (vkm) share of passenger car demand met by each engine type is shown in Figure 2. It can be seen that petrol-based ICE vehicles dominate the car until the 2040s, when electric vehicles (EVs) become the dominant engine for passenger cars. ICEs fueled by biofuel blends such as ethanol continue to be used globally over the whole of the projected time period.

While EVs dominate vkm travelled for cars, diesel remains the dominant fuel for freight transport using MCVs, HCVs, rail and shipping. This can be seen in Figure 3 where demand for diesel is met by both conventional 
diesel and alternative fossil diesel and which is sourced from CTL with and without CCS technologies. Consumption of ethanol as a $10 \%$ or $85 \%$ blend with petrol, biopetrol and alternative fossil petrol is also high. These fuels are used in cars, 2-3 wheelers, buses and LCVs. Consumption of electricity increases to 2060 given its use in EVs and passenger trains.

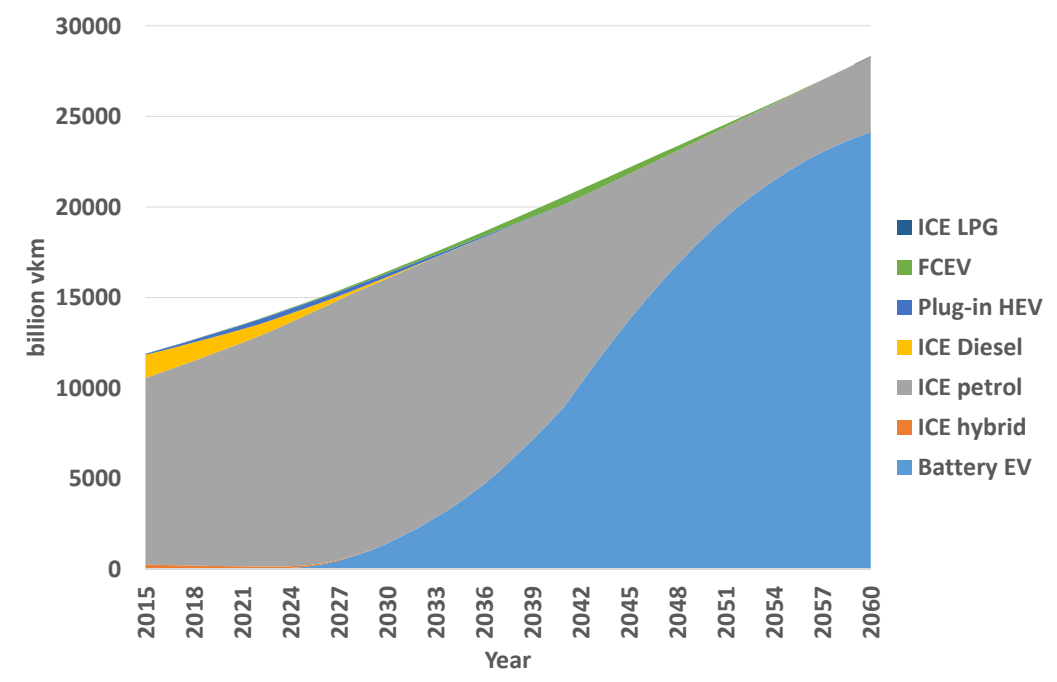

Figure 2. Projected global billion vkm travelled per engine type for cars to the year 2060 under Scenario 1

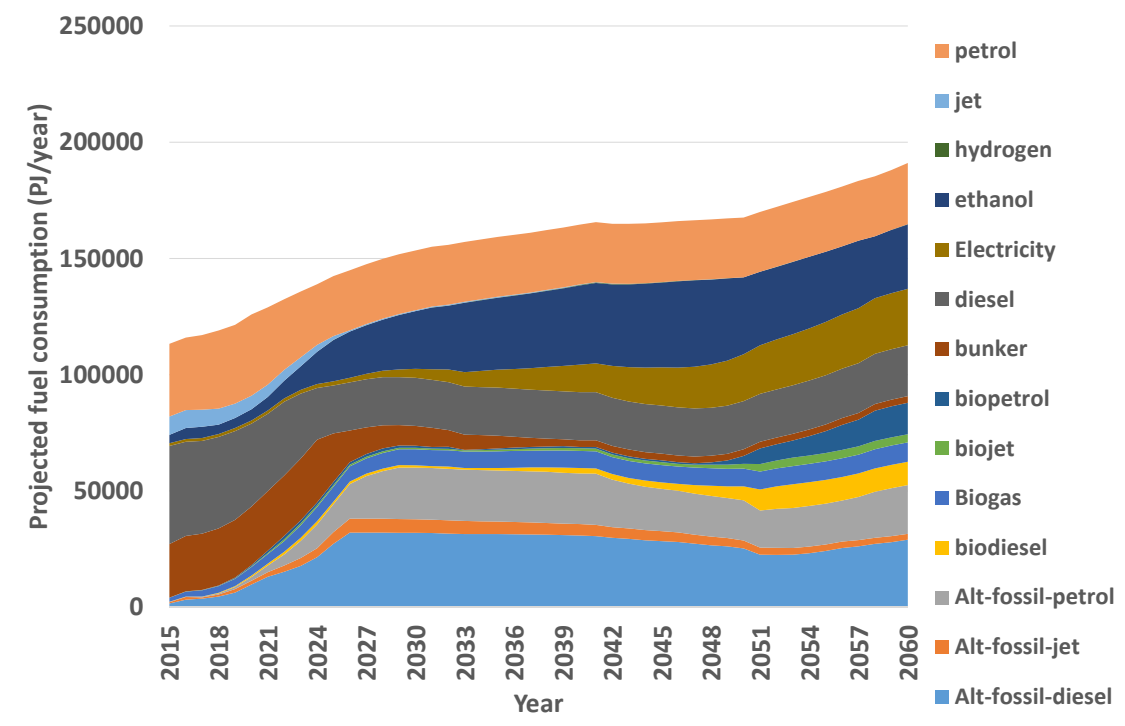

Figure 3. Projected global fuel consumption for all modes of transport to the year 2060 under Scenario 1

\subsection{Scenario 2}

The projected global total passenger car vkm demand met by each engine type is not shown as there is no difference between this and the result under Scenario 1, therefore a higher carbon price is not a driver of alternative engine uptake across this interval. The projected global fuel consumption is shown in Figure 4. This is also similar to the result under Scenario 1, however, in this case biofuel consumption is reduced, particularly from the year 2050 onwards. This can also be seen on examination of Table 1 , which compares the scenarios under broad fuel categories in the year 2060. It is also worth noting that there is greater consumption of fossil fuels under Scenario 2 and that the consumption of electricity is very similar. 


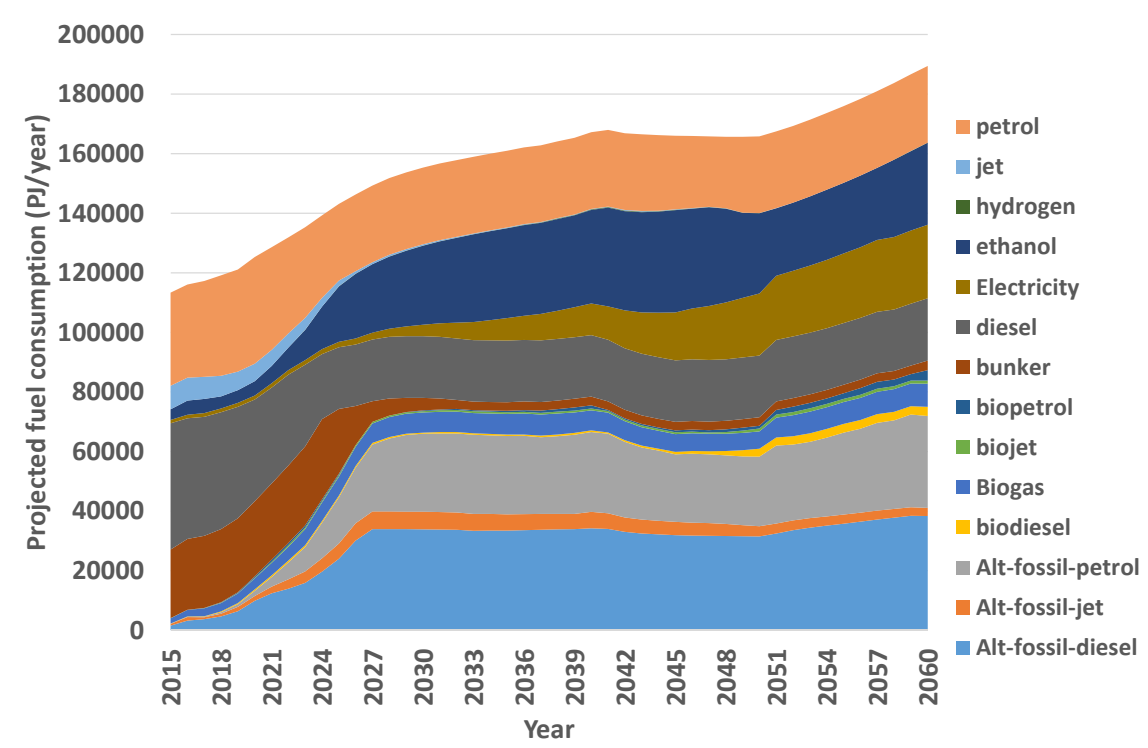

Figure 4. Projected global fuel consumption for all modes of transport to the year 2060 under Scenario 2

Table 1. Projected year 2060 global fuel consumption for broad fuel categories

\begin{tabular}{|l|l|l|}
\hline Fuel category & Scenario 1 (PJ/year) & Scenario 2 (PJ/year) \\
\hline Fossil fuel based & 103,550 & 121,870 \\
\hline Electricity & 24,340 & 24,730 \\
\hline Hydrogen & 0.85 & 0.03 \\
\hline Biofuel & 63,170 & 42,870 \\
\hline
\end{tabular}

\section{CONCLUSION}

By including the principle of 'learning-by-doing', GALLM-T has been shown to simultaneously project the cost and uptake of alternative transport technologies. As far as the authors are aware, this is the only model of its kind which includes experience curves for transport technologies.

GALLM-T projects that transformation will occur in the transport sector even under a low carbon price scenario. The transformation is driven by the lower cost of electric vehicles. In addition, there is sufficient lignocellulosic biomass available for production of biofuels, most notably ethanol, which reduces emissions from petrol-based ICEs. However, the use of alternative fossil-based fuels is projected to expand, which increase emissions when CCS is not used in these fuel conversion technologies. This is in contrast with IEA projections under their New Policies scenario which have the share of oil-based fuels remaining high $(85 \%)$, followed by other fuels at 7\%, biofuels at $6 \%$ and electricity at 4\% only by 2040 (IEA, 2016).

\section{REFERENCES}

BNEF . (2017). Electric vehicle outlook 2017. Retrieved from Bloomberg New Energy Finance: http://data.bloomberglp.com/bnef/sites/14/2017/07/BNEF_EVO_2017_ExecutiveSummary.pdf

Brinsmead, T. S., Graham, P., Hayward, J., Ratnam, E. L., \& Reedman, L. (2015). Future Energy Storage Trends: An Assessment of the Economic Viability, Potential Uptake and Impacts of Electrical Energy Storage on the NEM 2015-2035. CSIRO for AEMC.

Campbell, P. (2017, May 20). Electric car costs forecast to hit parity with petrol vehicles. Retrieved from Financial Times: https://www.ft.com/content/6e475f18-3c85-11e7-ac89-b01 cc67cfeec?mhq5j=e2

Croxton, K., Gendron, B., \& Magnanti, T. (2003). A comparison of mixed-integer programming models for nonconvex piecewise linear cost minimization problems. Management Science, 49(9), 1268-1273.

de Boor, C. (1973). Good approximation by splines with variable knots. In ISNM, Spline functions and approximation theory (Vol. 21, pp. 57-72). Basel: Birkhauser-Verlag. 
Grübler, A., Nakićenović, N., \& Victor, D. (1999). Dynamics of energy technologies and global change. Energy Policy, 27, 247-280.

Havlik, P., Schneider, U., Schmid, E., Böttcher, H., Fritz, S., Skalský, R., \& Obersteiner, M. (2011). Global land-use implications of first and second generation biofuels targets. Energy Policy, 39(10), 56905702.

Hayward, J., \& Graham, P. (2013). A global and local endogenous experience curve model for projecting future uptake and cost of electricity generation technologies. Energy Economics, 537-548.

IEA. (2016). World Energy Outlook. Paris, France: OECD.

Kypreos, S., Barreto, L., Capros, P., \& Messner, S. (2000). ERIS: A model prototype with endogenous technological change. Int. J. Global Energy Issues, 14(1-4), 374-397.

McDonald, A., \& Schrattenholzer, L. (2001). Learning rates for energy technologies. Energy Policy, 29, $255-$ 261.

Offer, G., Howey, D., Contestabile, M., R, C., \& Brandon, N. (2010). Compartive analysis of battery electric, hydrogen fuel cell and hybrid vehicles in a future sustainable road transport system. Energy Policy, 38(1), 24-29.

Rebennack, S. (2016). Computing tight bounds via piecewise linear functions through the example of circle cutting problems. Mathematical Methods of Operations Research, 1-55.

Sims, R., Schaeffer, R., Creutzig, F., Cruz-Núňez, D'Agosto, M., Dimitriu, D., . . Tiwari, G. (2014). Transport. In O. Edenhofer, R. Pichs-Madruga, Y. Sokona, E. Farahani, S. Kadner, K. Seyboth, . . . J. Minx, Climate Change 2014: Mitigation of Climate Change. Contribution of Working Group III to the Fifth Assessment Report of the Intergovernmental Panel on Climate Change. Cambridge, United Kingdom and New York, NY, USA: Cambridge University Press.

Smith, K., Adams, P., Baynes, T., Brinsmead, T., Hatfield-Dodds, S., Ferrier, S., . . . Nolan, M. (2017). Assessing risks and opportunities for Australia's future in a novel integrated assessment framework: the GNOME.3 suite for the Australian National Outlook. MODSIM.

Stephen, E., \& Eaves, J. (2004, May 3). A cost comparison of fuel-cell and battery electric vehicles. Journal of Power Sources, 130(1-2), 208-212.

Thomas, C. (2009). Fuel cell and battery electric vehicles compared. International Journal of Hydrogen Energy, 34(15), 6005-6020.

Vielma, J., Ahmed, S., \& Nemhauser, G. (2010). Mixed-integer models for nonseparable piecewise-linear optimization: unifying framework and extensions. Operations Research, 58(2), 303-315. 